\title{
ChemComm
}

\section{Tripodal molecules for the promotion of phosphoester hydrolysis $\dagger$}

\author{
Cite this: Chem. Commun., 2014, \\ 50, 6217 \\ Received 15th January 2014, \\ Accepted 23rd April 2014
}

DOI: $10.1039 / \mathrm{c} 4 \mathrm{cc} 00333 \mathrm{k}$

www.rsc.org/chemcomm Jennifer R. Hiscock, ${ }^{a}$ Mark R. Sambrook, ${ }^{b}$ Philippa B. Cranwell, ${ }^{a}$ Pat Watts,
Jack C. Vincent, ${ }^{b}$ David J. Xuereb, ${ }^{a}$ Neil J. Wells, ${ }^{a}$ Robert Raja ${ }^{a}$ and Philip A. Gale*a
A series of low molecular weight tripodal amide/histidine-containing compounds (1-2) have been synthesised and shown to increase the rate of bis-(p-nitrophenyl) phosphate (BNPP) and soman (GD) breakdown in buffered aqueous solution.

Organophosphorus (OP) nerve agents (NAs) are a class of chemical warfare agents that include the G-series such as sarin (GB) and soman (GD), and the V-series including VX. These compounds are highly toxic to biological systems as they inhibit the function of the enzyme acetylcholinesterase. ${ }^{1}$ Our interest in anion (and in particular phosphate) complexation led us to study the application of hydrogen bond donor systems in the recognition of OP NAs such as GD. ${ }^{2,3}$ Over the last thirty years much effort has been devoted to the synthesis of catalysts capable of mimicking the rate enhancing properties of naturally occurring enzymes. ${ }^{4-11}$ More recently there has been a concerted effort to utilise synthetic, peptide based molecules as organocatalysts, eliminating the need for metal ions in these systems. ${ }^{12-14}$ Histidine contains an imidazole group that when incorporated into a molecular/peptide structure can result in the catalysis of hydrolysis reactions due to its acid/base properties. ${ }^{15-17}$ Breslow and co-workers pioneered the use of bis-imidazoles for phosphate ester hydrolysis. ${ }^{18,19}$ Later work by Schmuck and co-workers showed that the presence of a histidine residue in the structure of a catalyst is able to promote phosphoester hydrolysis. ${ }^{20}$

In this article we report the synthesis of two new organic tripodal molecules (1 and 2) appended with $\mathrm{N}$-acetyl-protected histidine residues and a model compound $\mathbf{3}$. There are a number of examples of tripodal hydrogen bond donating receptors for tetrahedral guest species including phosphates. ${ }^{21,22}$ The design of the molecules reported here was inspired by these previous reports in that the compounds may bind the nerve agent allowing the appended $\mathrm{N}$-acetyl-protected histidine residues to interact with the substrate.

\footnotetext{
${ }^{a}$ Chemistry, University of Southampton, Southampton, UK SO17 1BJ.

E-mail: philip.gale@soton.ac.uk; Fax: +44 (0)23 8059 6805; Tel: +44 (0)23 80593322

${ }^{b}$ Detection Department, Dstl Porton Down, Salisbury, SP\$ OJQ, UK.

E-mail: m.sambrook@dstl.gov.uk; Tel: +44 (0)1980613306

$\dagger$ Electronic supplementary information (ESI) available: Experimental detail, characterisation data for compound 1. See DOI: $10.1039 / \mathrm{c} 4 \mathrm{cc} 00333 \mathrm{k}$
}

Compound 1 was shown to significantly enhance the hydrolysis rate of GD at pD 6.5 in buffered solution (where $\mathrm{pD}=\mathrm{pH}+0.4$ ). We designed the tripodal systems to interact with NAs via multiple hydrogen bonding interactions that would both bind the substrate and potentially activate it towards hydrolysis. We have shown that these compounds enhance the breakdown rate of GD and BNPP (an activated DNA model ${ }^{23}$ ) in aqueous buffered solutions.

Compound 1 was synthesised by the reaction of tris(2-aminoethyl)amine (tren) with $\mathrm{N}$-acetyl-L-histidine monohydrate using $2-\left(1 \mathrm{H}^{-}\right.$ benzotriazole-1-yl)-1,1,3,3-tetramethyluronium hexafluorophosphate (HBTU) as the peptide coupling agent in a solution of $\mathrm{N}, \mathrm{N}$ dimethylformamide and $N, N$-diisopropylethylamine affording the product in $61 \%$ yield. Compound 2 was synthesised by the reaction of mono-BOC protected tris(2-aminoethyl)amine with two equivalents of methoxyacetic acid in chloroform, using 1,1'-carbonyldiimidazole (CDI) as the amide coupling agent affording the intermediate in $83 \%$ yield. Following a deprotection the resultant amine was reacted with $\mathrm{N}$-acetyl-L-histidine monohydrate under the same conditions resulting in a yield of $56 \%$. Compound 3 was synthesised by the reaction of tris(2-aminoethyl)amine with methoxyacetic acid in chloroform using CDI as the amide coupling agent affording the product in $22 \%$ yield.

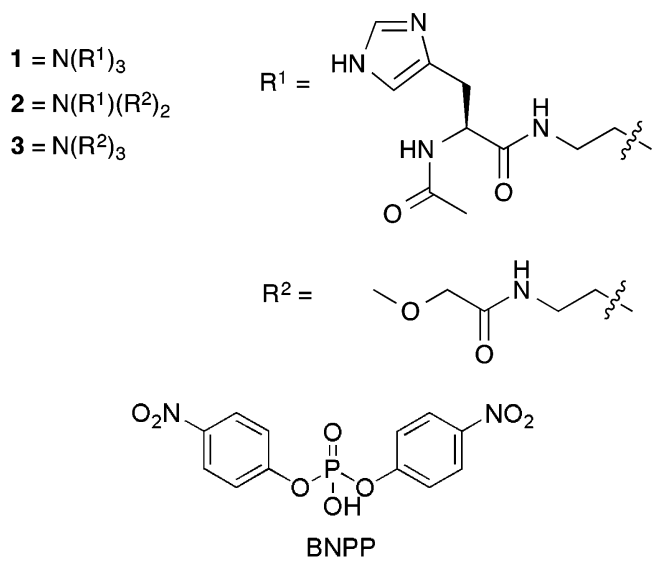

Studies of the breakdown of BNPP ( $5 \mathrm{mM})$ were conducted in aqueous 2,2-bis(hydroxymethyl)-2,2', $2^{\prime \prime}$-nitrilotriethanol (bis-tris) 
(20 mM) buffered stock solutions at $\mathrm{pH} 6.1$ or 7.1 and $20-23{ }^{\circ} \mathrm{C}$. The compounds were added to portions of these stock solutions in 20, 50 and $100 \mathrm{~mol} \%$ with respect to BNPP. Imidazole was added in 60, 150 and $300 \mathrm{~mol} \%$ as compound 1 contains three histidine groups per molecule therefore the mol\% of imidazole is matched to the maximum amount of histidine residues in solution in any one experiment. The breakdown of BNPP was monitored by UV-Vis spectroscopy, following the evolution of an absorbance band centred at $400 \mathrm{~nm}$ that corresponds to the formation of the breakdown product $p$-nitrophenolate.

A mechanism for the catalytic hydrolysis of BNPP by two histidine residues has been reported by Dixon and co-workers. ${ }^{24}$ In this example one of the histidine imidazole residues acts as a nucleophile while the second histidine imidazole residue acts as an acid, protonating the $p$-nitrophenolate leaving group.

Fig. 1 shows the formation of $p$-nitrophenolate as BNPP is hydrolysed over time at pH 6.1 and 7.1 in either the absence or presence of $100 \mathrm{~mol} \%$ of compound 1 and $300 \mathrm{~mol} \%$ imidazole. The greatest enhancement to the BNPP breakdown by compound 1 is observed at $\mathrm{pH}$ 6.1. This may be due to the increased proportion of protonated histidine residues available to supply a proton to the p-nitrophenolate leaving group. The same trend was observed upon addition of imidazole to the BNPP solution. BNPP breakdown was found to be enhanced to a much greater extent with the addition of compound $\mathbf{1}$ over imidazole. We postulate that this may be due to the structure of compound $\mathbf{1}$ which holds the three histidine residues in close proximity to each other and also to the substrate through the formation of hydrogen bonds via the amide donor groups, thus increasing the latter's effective concentration.

Fig. 2 shows the results of the same experiment conducted with compounds 2 and 3. Compound 2 contains a single histidine group and shows contrasting behaviour to compound 1. At pH 6.1 a lower degree of activity is observed when compared to compound $\mathbf{1}$. However at $\mathrm{pH} 7.1$ after $750 \mathrm{~h}$ a higher proportion of the BNPP has been broken down than observed with compound 1 . This may be

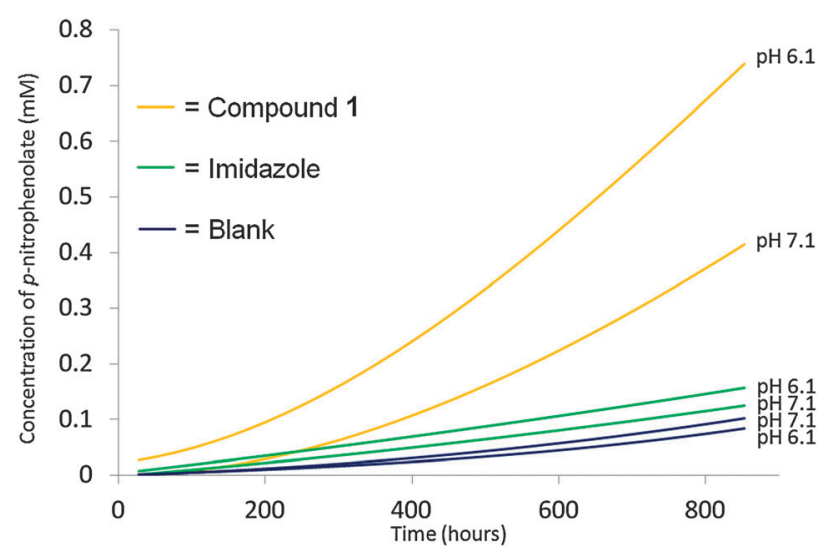

Fig. 1 Increasing concentration of $p$-nitrophenolate formed as BNPP is broken down under different $\mathrm{pH}$ conditions upon the addition of $100 \mathrm{~mol} \% / 300 \mathrm{~mol} \%$ compound 1 and imidazole respectively with respect to BNPP. The background rate of BNPP breakdown under these $\mathrm{pH}$ conditions was also monitored. Residual $R^{2}$ values for the individual fits $\leq 1 \%$. The background is taken from an average of two experiments. Individual fits and calculations can be found in the ESI. $\dagger$

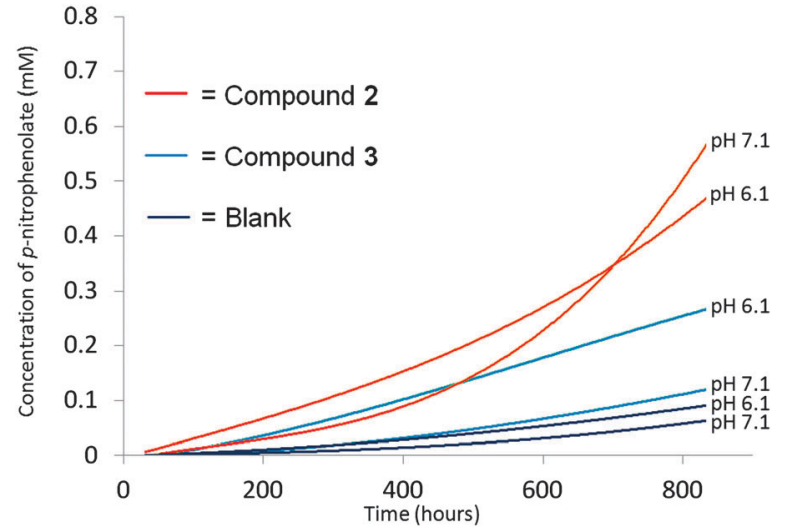

Fig. 2 Increasing concentration of $p$-nitrophenolate formed as BNPP is broken down under different $\mathrm{pH}$ conditions upon the addition of $100 \mathrm{~mol} \%$ compound $\mathbf{2}$ and $\mathbf{3}$ with respect to BNPP. The background rate of BNPP breakdown under these conditions was also monitored. Residual $R^{2}$ values for the individual fits $\leq 1 \%$. The background is taken from an average of two experiments. Individual fits and calculations can be found in the ESI. $\dagger$

because compound 2 is increasing the rate of BNPP breakdown through the utilisation of basic properties rather than a combination of acidic and basic properties as expected in the case of compound 3. Compound 3 contains no histidine groups however increased rates of BNPP breakdown are still observed at both $\mathrm{pH} 7.1$ and 6.1 with the greatest enhancement occurring at $\mathrm{pH}$ 6.1.

As compound 1 was found to be the most active of those compounds tested towards the breakdown of BNPP, it was also investigated for the potential to accelerate the hydrolysis of soman (GD). Compound 3 was used as a control in these experiments. Studies for the hydrolytic breakdown of GD (6 mM) were conducted in deuterated bis-tris $(20 \mathrm{mM})$ buffered stock solutions at $\mathrm{pD} 6.5$ (where $\mathrm{pD}=\mathrm{pH}+0.4$ ) and $20{ }^{\circ} \mathrm{C}$. The conditions chosen were identical to those found to enhance the breakdown of the model compound BNPP to the greatest extent. Compounds 1 and 3 were added to portions of these stock solutions in $100 \mathrm{~mol} \%$ to GD as appropriate and the breakdown of GD monitored using both ${ }^{1} \mathrm{H}$ and ${ }^{31} \mathrm{P}$ NMR.

Under the experimental conditions two hydrolysis products were identified. The main product was found to be pinacolyl methylphosphonate (PMP) formed via hydrolysis of the $\mathrm{P}-\mathrm{F}$ bond. Methylphosphonic acid (MP) was also detected in small quantities due to further hydrolysis of PMP.<smiles>CC(OP(C)(=O)F)C(C)(C)C</smiles>

GD<smiles>CC(OP(C)(=O)O)C(C)(C)C</smiles>

PMP<smiles>CP(=O)(O)O</smiles>

MP
Experiments with GD were run for 16-18 hour periods. A stack plot of ${ }^{1} \mathrm{H}$ NMR spectra from one of the hydrolysis experiments is shown in Fig. 3, with the resonances for GD and PMP labelled (see $\mathrm{ESI} \dagger$ for an analogous ${ }^{31} \mathrm{P}$ NMR plot). The concentrations of the different species present were calculated by integrating the ${ }^{1} \mathrm{H}$ and ${ }^{31} \mathrm{P}$ NMR spectra and relating these to the starting concentration of GD.

The percentage breakdown of GD far exceeds the rate of BNPP breakdown under similar conditions. This is in part due 


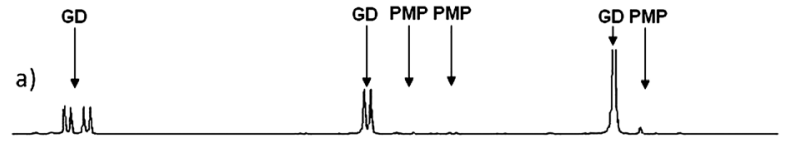

b)

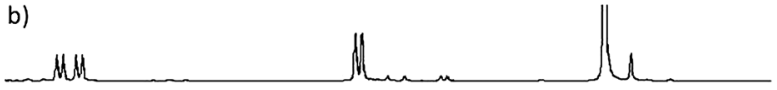
c) here

d) whth

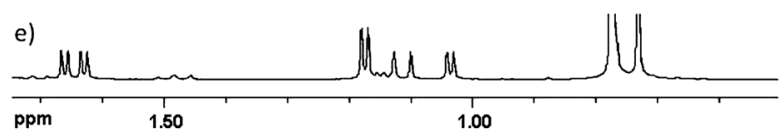

Fig. $3{ }^{1} \mathrm{H}$ NMR stack plot of the breakdown of GD in bis-tris (20 mM) buffered solutions at pD 6.5 in the presence of $100 \mathrm{~mol} \%$ of compounds 1 Time = (a) $0 \mathrm{~h}$ (b) $3 \mathrm{~h}$ (c) $7 \mathrm{~h}$ (d) $12 \mathrm{~h}$ and (e) $18 \mathrm{~h}$. (C) Crown Copyright, Dstl.

to the lower stability of GD vs. BNPP. The experimental data from the breakdown of GD in the presence of 100 and $50 \mathrm{~mol} \%$ compound 1 is shown in Fig. 4 . After $16 \mathrm{~h}$ there is approximately half the starting concentration of intact GD present in the samples that contain $100 \mathrm{~mol} \%$ compound $\mathbf{1}$, and with compound 3 only approximately $5 \%$ of the GD present has been hydrolysed. Although the results are less clear with the addition of $50 \mathrm{~mol} \%$ compound $\mathbf{1}$ it does appear that the rate of GD breakdown is reduced by decreasing the mol\% of compound 1 present. This data has been fitted to linear equations which can be found along with the relevant $R^{2}$ values in the ESI. $\dagger$

The association of dimethyl methylphosphonate (DMMP) and PMP with compound 3 was explored with the use of ${ }^{1} \mathrm{H}$ NMR titrations in MeCN- $d_{3}$. DMMP and PMP have similar structures to GD. Due to solubility and protonation issues host-guest combinations incorporating compounds 1, 2 and BNPP could not be explored. The results of these studies are shown in Fig. 5. Binding constants were calculated using WINEQN MR2 ${ }^{25}$ fitting the data

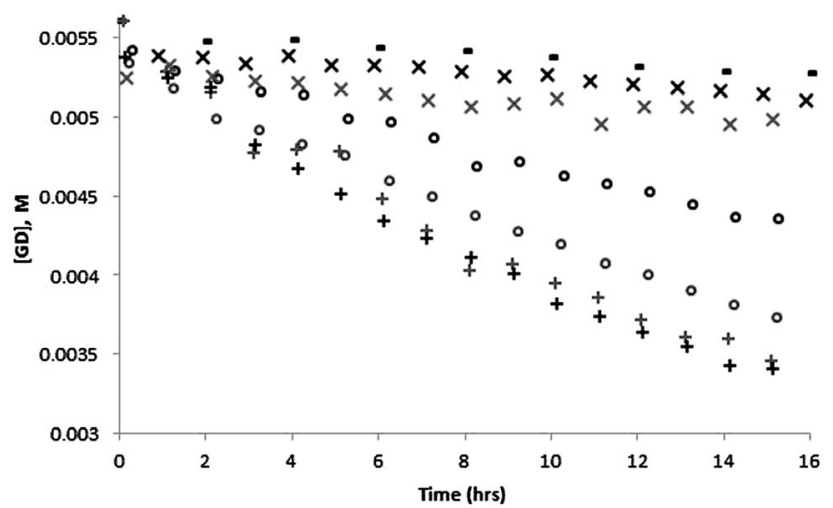

Fig. 4 Concentration of GD present as a function of time in bis-tris buffered solutions $(20 \mathrm{mM})$ at $\mathrm{PD} 6.5$ in the absence $(-)$ and presence of $100(+)$ and $50(O)$ mol\% compound $1(+)$ and 100 mol\% compound $3(x)$ as determined by ${ }^{1} \mathrm{H}$ NMR analysis. (C) Crown Copyright, Dstl. Two runs were performed for each compound at each concentration with the runs distinguished in the figure by the black and grey symbols.

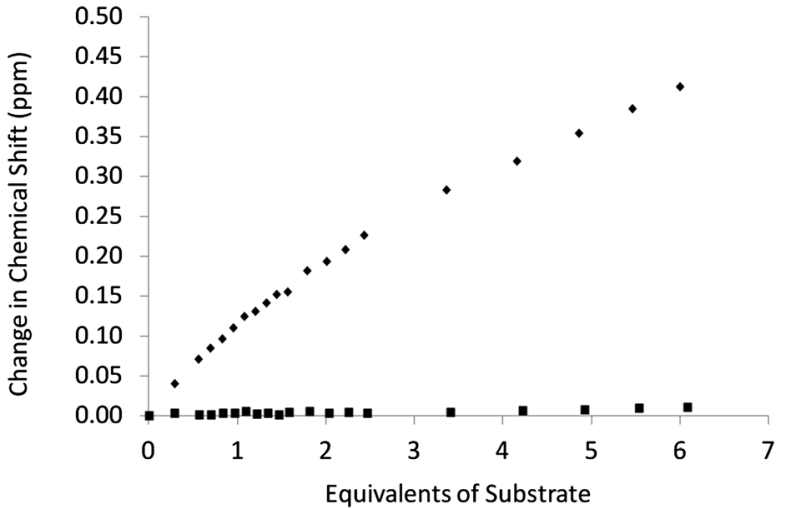

Fig. 5 Change in chemical shift of amide NH from compound $\mathbf{3}$ with the addition of PMP/DMMP $(\bullet / \mathbf{\square})$

to a $1: 1$ binding isotherm. An association between compound 3 and PMP was observed and fitting of the titration data to a $1: 1$ binding model gave a stability constant of $14 \mathrm{M}^{-1}$, through the formation of hydrogen bonds from the amide NH groups to PMP. No interaction was observed between compound 3 and DMMP. The higher affinity of compound 3 to PMP is presumably due to the higher polarity of PMP compared to DMMP and the presence of an extra hydrogen bond accepting/donating group in PMP.

These observations support the theory that compounds 1-3 are capable of forming host:guest complexes via hydrogen bonding interactions that may both bind the target organophosphate ester and activate it towards hydrolysis.

Single point ${ }^{1} \mathrm{H}$ NMR studies were also carried out with compound 3 and GD in $\mathrm{CDCl}_{3}$ in order to observe any potential host: guest association. Upon addition of two molar equivalents of GD to a solution of compound $3(0.01 \mathrm{M})$ a downfield shift of $0.014 \mathrm{ppm}$ was observed for the amide $\mathrm{NH}$ resonance, evidence supporting the formation of compound 3:GD complex, and preconcentration of GD.

We have shown that compound $\mathbf{1}$ is capable of enhancing the rate of GD hydrolysis. These results lead us to suggest that simple tripodal compounds containing amino acids such as histidine could be used for NA remediation.

We would like to thank the Defence Science and Technology Laboratory for funding through the Centre for Defence Enterprise scheme (JRH). We would also like to thank the ESPRC for a PhD studentship (DJX). MRS would like to thank Dstl for Research Scholarship funding. PAG thanks the Royal Society and the Wolfson Foundation for a Royal Society Wolfson Research Merit Award. The authors thank Dr James Jones (Dstl) for assistance with NMR.

\section{Notes and references}

1 K. Kim, O. G. Tsay, D. A. Atwood and D. G. Churchill, Chem. Rev., 2011, 111, 5345-5403.

2 M. R. Sambrook, J. R. Hiscock, A. Cook, A. C. Green, I. Holden, J. C. Vincent and P. A. Gale, Chem. Commun., 2012, 48, 5605-5607.

3 J. R. Hiscock, F. Piana, M. R. Sambrook, N. J. Wells, A. J. Clark, J. C. Vincent, N. Busschaert, R. C. D. Brown and P. A. Gale, Chem. Commun., 2013, 49, 9119-9121.

4 A. Blasko and T. C. Bruice, Acc. Chem. Res., 1999, 32, 475-484.

5 P. Dydio, W. I. Dzik, M. Lutz, B. de Bruin and J. N. H. Reek, Angew. Chem., Int. Ed., 2011, 50, 396-400. 
6 F. Giacalone, M. Gruttadauria, P. Agrigento and R. Noto, Chem. Soc. Rev., 2012, 41, 2406-2447.

7 R. Salvio, R. Cacciapaglia and L. Mandolini, J. Org. Chem., 2011, 76, 5438-5443.

8 B. M. Smith, Chem. Soc. Rev., 2008, 37, 470-478.

9 A. Sreedhara and J. A. Cowan, J. Biol. Inorg. Chem., 2001, 6, 337-347.

10 J. E. Taylor, S. D. Bull and J. M. J. Williams, Chem. Soc. Rev., 2012, 41, 2109-2121; N. H. Williams, B. Takasaki, M. Wall and J. Chin, Acc. Chem. Res., 1999, 32, 485-493.

11 F. Brandhuber, M. Zengerle, L. Porwol, A. Bierwisch, M. Koller, G. Reiter, F. Worek and S. Kubik, Chem. Commun., 2013, 49, 3425-3427.

12 X. H. Cao, G. Wang, R. C. Zhang, Y. Y. Wei, W. Wang, H. C. Sun and L. G. Chen, Org. Biomol. Chem., 2011, 9, 6487-6490.

13 G. D. Joly and E. N. Jacobsen, J. Am. Chem. Soc., 2004, 126, 4102-4103.

14 M. Wiesner, J. D. Revell and H. Wennemers, Angew. Chem., Int. Ed., 2008, 47, 1871-1874.

15 Y. Bai, Y. B. Ling, W. G. Shi, L. F. Cai, Q. Y. Jia, S. B. Jiang and K. L. Liu, ChemBioChem, 2011, 12, 2647-2658.
16 Y. Ma, X. Chen, M. Sun, R. Wan, C. Zhu, Y. Li and Y. Zhao, Amino Acids, 2008, 35, 251-256.

17 C. Schmuck, U. Michels and J. Dudaczek, Org. Biomol. Chem., 2009, 7, 4362-4368.

18 R. Breslow, P. Bovy and C. L. Hersh, J. Am. Chem. Soc., 1980, 102, 2115-2117.

19 R. Breslow, J. B. Doherty, G. Guillot and C. Lipsey, J. Am. Chem. Soc., 1978, 100, 3227-3229.

20 M. Merschky and C. Schmuck, Org. Biomol. Chem., 2009, 7, 4895-4903.

21 P. A. Gale, N. Busschaert, C. J. E. Haynes, L. E. Karagiannidis and I. L. Kirby, Chem. Soc. Rev., 2014, 43, 205-241.

22 M. Wenzel, J. R. Hiscock and P. A. Gale, Chem. Soc. Rev., 2011, 41, 480-520.

23 R. Kramer, Coord. Chem. Rev., 1999, 182, 243-261.

24 A. E. Rudolph, J. A. Stuckey, Y. Zhao, H. R. Matthews, W. A. Patton, J. Moss and J. E. Dixon, J. Biol. Chem., 1999, 274, 11824-11831.

25 M. J. Hynes, J. Chem. Soc., Dalton Trans., 1993, 311-312. 